\title{
Worldwide Acreage and Yield Response to International Price Change and Volatility: A Dynamic Panel Data Analysis for Wheat, Rice, Corn, and Soybeans
}

\author{
Mekbib G. Haile, Matthias Kalkuhl, and Joachim von Braun
}

\subsection{Introduction}

After about three decades of low and relatively stable prices of staple food commodities, the world has experienced a surge in the prices of many of these commodities since 2005. Such high prices are typically expected to bring about a supply response by which producers allocate more land to the agricultural sector and increase investment to improve yield growth (OECD 2008). The higher prices were, however, accompanied by higher volatility (Gilbert and Morgan 2010). Price volatility introduces output price risk, which has detrimental implications for producers' resource allocation and investment decisions (Sandmo 1971; Moschini and Hennessy 2001). Because agricultural producers in many developing countries are often unable to deal with (Binswanger and Rosenzweig 1986) and are unprotected from (Miranda and Helmberger 1988) the consequences of price volatility, they are exposed to the effects of international agricultural market price instability to the extent that the instability is transmitted to local markets. Yet Bellemare et al. (2013) pointed out that reducing commodity price volatility could benefit wealthier rural households more than poorer ones.

This is a stylistically edited version of our open-access paper published in the American Journal of Agricultural Economics (2015), doi: 10.1093/ajae/aav013.

M.G. Haile $(\square) \bullet$ M. Kalkuhl • J. von Braun

Center for Development Research (ZEF), University of Bonn, Bonn, Germany

e-mail: mekhaile@uni-bonn.de 
This study analyzes the supply responsiveness of the key world staple food commodities - namely, wheat, corn, soybeans, and rice-to changes in output prices and volatility. It assesses how global food commodity producers allocate cropland and how their production decisions are affected by changes in price levels and volatility. These are fundamental questions for designing policies related to agricultural growth and food supply. Additionally, the study provides relevant information on how quickly current scarcities in global food supply, which are indicated by high prices, can be overcome by increasing production in the short term.

The literature about estimating supply response to prices has a long history in agricultural economics (Houck and Ryan 1972; Lee and Helmberger 1985; Nerlove 1956). Nevertheless, there are various reasons for the renewed interest in the research about supply response. The majority of the previous empirical literature concentrated only on a few countries, without having to estimate the worldwide supply response to international prices. Furthermore, the impact of price volatility and price risk is rarely considered because the small number of observations limits the use of additional explanatory variables or because price risk has not been considered as an important factor at the global level. The prices of many agricultural commodities have become more volatile after 2005, resulting in new interest in the impacts of price risk and volatility on (global) food security. The current study addresses this debate from the supply-side perspective, that is, it attempts to assess the extent to which price risks reduce production and supply response to increasing price levels.

Many existing econometric analyses focused on national supply responses to domestic prices. In contrast, this paper investigates the worldwide aggregate supply response to international market prices for the key world staples. In doing so, this article makes the following major contributions: First, it provides updated shortand long-term supply elasticities, which indicate how major agricultural commodity producers have responded to the recent increase in global food prices and volatility. This reveals to what extent the global agricultural system is responding to emerging global food scarcities. Second, some empirical evidence suggests that acreage adjustments constitute the largest share of the supply response to output price in the short run (e.g., Roberts and Schlenker 2009), and therefore, both acreage and yield responses are estimated to examine this finding. And third, this study evaluates whether the recent increase in prices and price volatility poses an opportunity or a challenge to the aggregate agriculture sector in general and, in particular, agricultural producers. To this end, we use simulation analyses to assess the overall impacts of the agricultural commodity price dynamics on the worldwide supply of the aforementioned key staple crops during the 2006-2010 period.

This study differs from a related work by Haile et al. (2014) in terms of methodology and research question. They employed several time series models to investigate annual and intra-annual global acreage response, whereas the current study uses a panel econometric modeling approach that makes use of data in which international prices are assigned to the corresponding planting season of the respective country and crop. Thus, this paper estimates global supply response of the 
aforementioned agricultural commodities by employing a newly developed multicountry, crop- and calendar-specific, seasonally disaggregated panel data with price changes and price volatility applied accordingly. This is an alternative approach to modeling heterogeneous seasonal planting patterns on the global scale, which has the advantage of using a larger number of observations without sacrificing the underlying nature of the monthly time resolution of production decisions. In addition, this study investigates not only acreage but also yield supply response to prices and price risk. The joint consideration allows us to make inferences about the global production response (as the product of acreage and yield response), which is relevant for policymakers. Finally, and importantly, this article assesses the net impacts of the recent agricultural commodity price dynamics on acreage, yield, and production of the key interest crops.

\subsection{Related Literature}

This study builds on the extensive agricultural economics literature about the estimation of agricultural supply response. Elasticities in a supply response model refer to the speed and size of adjustments in desired output relative to expected output prices. Neither the desired output nor the expected price is observable, however. The empirical literature employed different types of proxies for these variables, which could affect the results obtained. We provide a brief review of the literature with respect to the alternative proxies for these two variables.

In terms of the proxy for expected output prices, the literature did not provide unambiguous evidence regarding which expectation model should be used for empirical agricultural supply response estimation (Nerlove and Bessler 2001; Shideed and White 1989). Expectation formation hypotheses, widely applied in the supply response literature, include naive expectation (Ezekiel 1938), whereby expected prices are assumed to be equal to the latest observed prices; adaptive expectation (Nerlove 1958), whereby farmers are assumed to revise their expectations depending on past errors; and rational expectation (Muth 1961), which assumes that expectations are consistent with the underlying market structure and that economic agents make efficient use of all available information. Other research has focused on modeling supply response by using quasi-rational price expectations (Holt and McKenzie 2003), which is consistent with price prediction from a reduced-form dynamic regression equation. Futures prices are also used as a proxy for price expectations (Gardner 1976).

The naive and adaptive expectation hypotheses have been criticized because they are backward-looking (Nickell 1985); in other words, they ignore that the dynamics of price expectations of decision-makers can influence futures prices. Although the rational expectation hypothesis can be forward-looking, it implies that economic agents make efficient use of all available information, which may not be the case when some information is costly or difficult to process (Chavas 2000). Additionally, the rational expectation hypothesis is not supported by some experimental and survey datasets (Nelson and Bessler 1992). It is also doubtful whether futures 
prices are applicable as a proxy in supply analyses for countries where farmers are unable to make any futures transactions and have no access to information from exchange markets. Moreover, some empirical evidence showed that heterogeneous expectations coexist among agricultural producers (Chavas 2000).

Following Nerlove (1958), several empirical supply response models employ the adaptive expectation hypothesis and its variants. Askari and Cummings (1977), and later Nerlove and Bessler (2001), provided a thorough review of such literature. Some recent examples are Yu et al. (2012), Vitale et al. (2009), and de Menezes and Piketty (2012). Aradhyula and Holt (1989) employed the rational expectation hypothesis to investigate broiler supply in the USA; Eckstein (1984) and Lansink (1999) applied it to estimate crop acreage elasticities using aggregate agricultural data and farm-level data, respectively. Moreover, other empirical applications showed the relevance of the quasi-rational expectation approach in their supply models (Holt and McKenzie 2003; Nerlove and Fornari 1998). Lastly, Gardner (1976), Lin and Dismukes (2007), Liang et al. (2011), and Hausman (2012) are a few examples of studies that used harvest-time futures prices as a proxy for farmers' price expectations during planting season.

The empirical agricultural supply response literature has often used acreage, yield, or production as a proxy for desired output supply. Several studies preferred to use acreage when modeling output supply response (Coyle 1993; Haile et al. 2014) because acreage, unlike observed output, is not influenced by external shocks that occur after planting. However, acreage elasticities may only serve as a lower bound for the total supply elasticity (Rao 1989) because the latter depends also on how yield responds to prices. Several studies estimated both acreage and yield responses to prices (Weersink et al. 2010; Yu et al. 2012). When how supply responds to output prices is trivial (via acreage or yield), total observed production is another proxy used in the literature to estimate output supply response (Coyle 1999). Because "external" factors such as weather and pest shocks — which usually happen after farmers make their production decisions and are hardly predictable, such that farmers are unable to consider them when making production decisionsinfluence total observed production, the estimated supply response may not reflect how farmers actually respond to prices.

There is, however, another proxy used in recent studies-total caloric production, which is the sum of the caloric value of specific crops (Roberts and Schlenker 2009, 2013). This proxy implicitly assumes that the crops in the caloric aggregate are perfectly substitutable, which is less plausible as it assumes identical land and other input requirements for each crop. This ignores the possibility that producers might switch crops as a result of changes in relative prices by shifting out land from "low-demand" crops. This is supported by literature that showed acreage expansion of "high-demand" crops such as corn (Abbott et al. 2011; Goodwin et al. 2012). Such aggregation excludes intercrop acreage and other input shifts, which, by definition, implies that aggregate output elasticities are likely to be smaller than crop-specific elasticities. This is consistent with several empirical studies that found statistically significant cross-price elasticities of crop acreages. Hendricks et al. (2014), for instance, concluded that most of the acreage response to prices of corn 
and soybeans in the USA occurs through substitution rather than area expansion. Moreover, aggregation of crops conceals any implications for and effects of cropspecific policies with respect to changing intra-commodity price relationships.

On the other hand, output supply can be estimated at the plot or farm level, whereby farm size, soil quality, and other farm characteristics can be controlled for; at the household level, which enables better understanding of farmers' supply behaviors; or at larger aggregation scopes (such as at national, regional, or global levels), which have methodological limitations to capture the effects of contextual factors but still enable sufficient measurement of supply responsiveness. Yet, the estimation of aggregate agricultural supply response to changing price incentives has crucial implications for economic growth and poverty alleviation in economies in which the agricultural sector constitutes a sizable share of the national income.

Although there are several farm- and micro-level studies (e.g., Lansink 1999; Vitale et al. 2009; Yu et al. 2012) and quite a few national-level studies (e.g., Barr et al. 2009; de Menezes and Piketty 2012), global-level studies are scarce. Nevertheless, cross-country analyses are conducted using a certain group of countries to determine the role of prices on agricultural supply. Peterson (1979), for instance, found agricultural supply in developing countries to be fairly responsive to crop prices (estimated long-run elasticities range between 1.25 and 1.66). On the other hand, using a sample of 58 countries between 1969 and 1978, Binswanger et al. (1987) found that agricultural supply responded weakly to price incentives but strongly to non-price factors. A more recent cross-country study by Subervie (2008), based on a sample of 25 developing countries between 1961 and 2002, found a rather small, but statistically significant, aggregate supply elasticity of 0.04 . Findings from Imai et al. (2011), which used data from a panel of ten Asian countries, and other crop-disaggregated studies that found much larger supply elasticities hinted that such aggregation of crops could result in small supply elasticities.

The other scope is when supply is aggregated across countries and crops. Two related studies by Roberts and Schlenker $(2009,2013)$ estimated the caloricaggregated world supply and demand of staple crops-corn, wheat, soybeans, and rice-and found supply elasticities in the range of 0.06-0.12. They used lagged weather shocks, which are approximated by deviations of yield from trend, to identify the supply elasticity of agricultural commodities. Hendricks et al. (2015) replicated Roberts and Schlenker's analysis and found little difference between their estimates, which controlled for the realized yield shock, and those of Roberts and Schlenker, which used weather shocks in the previous year as an instrument for potentially endogenous expected prices. These authors also suggested that using planted acreage as a dependent variable can reduce this endogeneity bias in the supply elasticity estimates. In line with this suggestion, Haile et al. (2014) aggregated the global acreage of staple food to estimate crop-specific world supply elasticities. The elasticities were found to fall in a range between 0.03 (for rice) and 0.34 (for soybeans).

This study differs from the literature discussed above in terms of the level of aggregation employed for the dependent variables and the proxy used for expected prices. Besides using crop acreage, yield and production as alternative proxies for 
the desired output supply, these variables are aggregated at the global level for each crop. Nevertheless, the aggregation retains the panel feature of the data, which enables us to control for heterogeneity across countries. For example, we made use of the country- and crop-specific planting and harvesting seasons to identify the suitable proxy for price expectation in each country and for each crop.

Our proxy for expected prices differs from those used in the literature. In this study, we used world prices during planting season as a proxy for the prices anticipated by farmers in each country; in other words, we estimated the crop supply response to changes in world prices rather than to specific domestic prices. Thus, unlike the commonly understood agricultural supply response, which estimates how output supply responds to changes in the domestic prices in the producers' own countries, we estimated the responses (in terms of production, area, and yield) to changes in international prices. These two supply response estimates are identical under the assumption of complete transmission of international prices to domestic producer prices. However, they could be different in case of incomplete price transmission—an argument which is supported by the literature (e.g., Kalkuhl 2014). Finally, with the exception of Subervie (2008), none of the abovementioned cross-country panel studies and, to our knowledge, no worldwide aggregated supply response studies, except Haile et al. (2014), have accounted for price volatility (price risk) in the respective supply models.

\subsection{Conceptual Framework}

The literature on supply response has gone through several important empirical and theoretical modifications, and two major frameworks have been developed. The first approach is the Nerlovian partial adjustment model, which allows for analyzing both the speed and the level of adjustment from the actual output to desired output. The second framework is the supply function approach, which is derived from the profit-maximizing framework. The framework requires detailed input price data and simultaneous estimation of input demand and output supply equations. However, input markets — in particular land and labor markets - are either missing or imperfect in many countries. Moreover, our main interest lies in the output supply function. Thus, the econometric approach used in the present study is in line with the partial adjustment framework, and the approach is enhanced with dynamic response, alternative price expectation assumptions, and the introduction of pricerisk variables.

Models of the supply response of a crop can be formulated in terms of output, area, or yield response. For instance, the desired output of a certain crop in period $t$ is a function of expected output prices and a number of other exogenous factors (Braulke 1982):

$$
Q_{t}^{\mathrm{d}}=\beta_{1}+\beta_{2} p_{t}^{\mathrm{e}}+\beta_{3} Z_{t}+\varepsilon_{t}
$$


where $Q_{t}^{\mathrm{d}}$ denotes the desired output in period $t ; p_{t}^{\mathrm{e}}$ is a vector of the expected price of the crop under consideration and of other competing crops; $Z_{t}$ is a set of other exogenous variables, including fixed and variable input prices, climate variables, and technological change; $\varepsilon_{t}$ accounts for unobserved random factors affecting crop production with zero expected mean; and $\beta_{i}$ are the parameters to be estimated. Output (determined by area and yield) adjustments are usually delayed by one or two agricultural production cycles because of a lack of resources. To account for such time lags in agricultural supply response, it is important to apply a dynamic approach. A supply response is usually a two-stage process. Because harvest-time prices are not realized during the time of planting, producers make acreage allocation decisions conditional on expected prices at the first stage. As in the production equation above, the desired area to be cultivated for a certain crop at time $t\left(A_{t}^{\mathrm{d}}\right)$ is determined by expected own-crop and competing crop prices and other non-price factors:

$$
A_{t}^{\mathrm{d}}=\alpha_{1}+\alpha_{2} p_{t}^{\mathrm{e}}+\alpha_{3} Z_{t}+\varepsilon_{t}
$$

Given the acreage allocation for each crop, farmers then determine crop yield based on other inputs and climate conditions. During the growing period, they may make revisions to their production practices by adjusting their input quantity, input quality, and crop protection. Hence, the desired yield of each crop is defined similarly to Eqs. (7.1) and (7.2) except that the output price vector includes only the crop's own price.

It is important to emphasize that we used international prices instead of domestic prices for our empirical analysis. Given a price transmission elasticity $\eta$, we can substitute the domestic log price $p_{t}^{\mathrm{e}}$ with the transmitted international price $p_{t}^{\mathrm{e}}=$ $\eta p_{t}^{\text {e,int }}$ in Eqs. (7.1) and (7.2). This substitution gives:

$$
Q_{t}^{\mathrm{d}}=\beta_{1}+\beta_{2} \eta p_{t}^{\mathrm{e}, \text { int }}+\beta_{3} Z_{t}+\varepsilon_{t}=\beta_{1}+\tilde{\beta}_{2} p_{t}^{\mathrm{e}, \text { int }}+\beta_{3} Z_{t}+\varepsilon_{t}
$$

and

$$
A_{t}^{\mathrm{d}}=\alpha_{1}+\alpha_{2} \eta p_{t}^{\mathrm{e}, \text { int }}+\alpha_{3} Z_{t}+\varepsilon_{t}=\alpha_{1}+\tilde{\alpha}_{2} p_{t}^{\mathrm{e}, \text { int }}+\alpha_{3} Z_{t}+\varepsilon_{t}
$$

which are structurally equivalent to Eqs. (7.1) and (7.2). The estimated supply response elasticities $\tilde{\beta}_{2}$ and $\tilde{\alpha}_{2}$, however, implicitly consider the imperfect transmission of prices from international to domestic markets. Hence, the supply response concept used in this paper is an aggregate response that consists of two parts: the (imperfect) transmission of global prices to domestic producer prices and the genuine supply response to expected domestic producer prices. The latter is typically estimated in conventional supply response models. 


\subsection{Data}

The econometric model relies on a comprehensive database covering the period 1961-2010. The empirical model uses global- and country-level data in order to estimate global production, acreage, and yield responses for the key staple crops in the world. Data on planted acreage were obtained from several relevant national statistical sources, ${ }^{1}$ whereas harvested acreage, production, and yield for all countries were obtained from the Food and Agriculture Organization (FAO) of the United Nations. Area harvested serves as a proxy for planted area if data on the latter are unavailable. International spot market output prices and different types of fertilizer prices and price indices are obtained from the World Bank's commodity price database. All commodity futures prices were obtained from the Bloomberg database. The 32 countries or regions included in this study, with the rest of world (ROW) aggregated into a separate entity, are reported in Table 7.6 in Appendix. ${ }^{2}$

A producer may choose to cultivate different crops at planting time. Therefore, it is worthwhile to consider price, price risk, and other information available to the farmer during the planting season. Accordingly, we used crop calendar information to identify the major planting seasons in each country in order to obtain countryspecific spot and futures prices, measures of price risk and yield shocks, and input prices. ${ }^{3}$

Because actual prices are not realized during planting, we modeled farmers' price expectations using the available relevant information about world spot and world futures prices during planting. In the empirical model, own-crop and competing crop spot prices observed in the month before the start of planting are used since they contain more recent price information for farmers. Alternatively, harvest-time futures prices quoted in the months prior to planting are used. The use of these two price series to formulate producers' price expectations makes our supply response models adaptive as well as forward-looking. Because planting pattern varies across countries and crops, both the futures and spot prices of each crop are country specific. For countries in the ROW, we used annual average spot and futures prices.

The degree of transmission of international prices to national markets, $\eta$, can vary between countries (so do the "genuine" supply elasticities $\alpha_{2}$ and $\beta_{2}$ ). Comparisons of the global and national supply response elasticities from the literature indicated that price transmission from world to domestic prices is imperfect or absent in some countries. Consequently, producers' response to international price changes and volatility — which is the focus of this study — is expected to be smaller. Nevertheless,

\footnotetext{
${ }^{1}$ Data sources are available in Table 7.6 in Appendix.

${ }^{2}$ Countries with a global acreage share of less than half a percent are grouped in the rest-of-world category.

${ }^{3}$ The crop calendar for emerging and developing countries is obtained from the Global Information and Early Warning System (GIEWS) of the FAO, and the crop calendar for the advanced economies is from the Office of the Chief Economist (OCE) of the United States Department of Agriculture (USDA).
} 
empirical evidence shows that world prices are a significant source of variation in domestic prices (Mundlak and Larson 1992). Recent empirical literature also shows that domestic markets are integrated into world markets mostly through the adjustment of domestic prices to deviations from the long-run domestic-world price relationship (Baquedano and Liefert 2014; Kalkuhl 2014). Estimating the countryspecific transmission elasticity would allow us to decompose the supply response into its transmission component $(\eta)$ and its "genuine" supply response $\left(\alpha_{2}\right.$ and $\left.\beta_{2}\right)$ for each country. However, as this is empirically cumbersome and requires long price series that are difficult to obtain for the country studied in this paper, we empirically estimated the average global response to international price changes, disregarding any possible heterogeneity in the price transmission and the "genuine" supply response.

We included own and cross volatility of international spot prices in order to capture output price risk. For price volatility we used the standard deviation of the $\log$ returns (that is, first differences instead of levels of log prices) in order to use the de-trended price series. The price-risk measures show country-specific output price variability in the 12 months preceding the start of the planting season of each crop in each country. Table 7.1 presents international price volatility along with the respective average real prices for all four crops. The volatility of world prices of these crops, measured by the moving standard deviation of monthly logarithmic prices, was higher in the recent decade relative to earlier periods, although it was not as high as in the 1970s. Any high degree of collinearity between the price level and volatility of a crop might be of concern for our empirical estimation; therefore, we computed both the Pearson's rank and Spearman's rank correlation coefficient for each crop, establishing a relationship between their own price and their ownprice volatility. The correlation coefficients are positive and statistically significant in all cases, with wheat and corn exhibiting the highest Pearson's rank (Spearman's rank) correlation coefficients of $0.51(0.53)$ and 0.45 (0.56), respectively. Further collinearity diagnostic analyses of all price and volatility variables, such as the

Table 7.1 International price volatility and levels for wheat, corn, soybeans, and rice

\begin{tabular}{l|l|l|l|l|l|l|l|l}
\hline \multirow{2}{*}{ Period } & \multicolumn{9}{l}{ Price volatility } & \multicolumn{2}{l}{ Price level } \\
\cline { 2 - 10 } & Wheat & Corn & Soybeans & Rice & Wheat & Corn & Soybeans & Rice \\
\hline $1961-1970$ & 0.062 & 0.069 & 0.082 & 0.104 & 258 & 220 & 467 & 594 \\
\hline $1971-1980$ & 0.157 & 0.122 & 0.175 & 0.194 & 267 & 210 & 502 & 598 \\
\hline $1981-1990$ & 0.089 & 0.135 & 0.121 & 0.125 & 182 & 140 & 320 & 331 \\
\hline $1991-2000$ & 0.131 & 0.127 & 0.080 & 0.136 & 149 & 113 & 256 & 285 \\
\hline $2001-2010$ & 0.153 & 0.142 & 0.148 & 0.127 & 191 & 133 & 323 & 328 \\
\hline $2001-2005$ & 0.113 & 0.107 & 0.132 & 0.086 & 160 & 111 & 273 & 236 \\
\hline $2006-2011$ & 0.214 & 0.193 & 0.163 & 0.160 & 227 & 169 & 384 & 423 \\
\hline
\end{tabular}

Note: Price volatility is measured by the standard deviation of logarithmic monthly prices using the World Bank international prices. Prices are in real 2005 US dollars per metric ton. The figures in each row refer to average values of the annualized volatilities and prices over the respective decade 
variance inflation factor (VIF), indicate that multicollinearity is not a serious problem in our data.

We included yield shocks calculated as deviations from country- and cropspecific trends in our empirical supply models. The deviations may have been caused by weather shocks, pest infestations, or other factors; our assumption is that these deviations from the yield trends could serve as proxy for producers' yield expectations. Following Roberts and Schlenker (2009), the yield shocks are the jackknifed residuals from separate yield-on-trend regressions for each crop in each country. A positive deviation entails good yield expectations, implying a positive effect on crop supply. We aggregated the crop yields across the remaining countries in the ROW to generate yield shocks for each crop.

Fertilizer price indices are used as proxies for production costs in this paper. The weights used by the World Bank shows that the fertilizer price index considers the prices of natural phosphate rock, phosphate, potassium, and nitrogenous fertilizers. The fertilizer price index is also crop and country specific, depending on the planting pattern of a crop in a country. The fertilizer price index in the month prior to the start of planting was used in the calculations.

\subsection{Econometric Model}

Given the above theoretical model and assuming there are $K$ countries observed over $T$ periods, the supply functions of the four crops can be expressed generally as

$$
\begin{gathered}
Q_{i k t}=\pi_{i} Q_{i k, t-1}+\sum_{j=1}^{4} \alpha_{i j} p_{j k, t_{i, k}}+\sum_{j=1}^{4} \varphi_{i j} \operatorname{vol}(p)_{j k, t_{i, k}}+\lambda_{i 1} w_{i k, t_{i, k}}+\lambda_{i 2} \mathrm{YS}_{i k, t_{i, k}} \\
+\mu_{i t}+\eta_{i k}+u_{i k t}
\end{gathered}
$$

where $Q_{i k t}$ denotes the total production (or area under cultivation) of crop $i$ $(1=$ wheat, $2=$ corn, $3=$ soybeans, and $4=$ rice $), p_{j k, t, k}$ denotes a vector of either spot or futures prices that are used as a proxy for expected own-crop and competing crop prices at planting time, $\operatorname{vol}(p)_{j k, t_{i, k}}$ is a vector of the volatility measures for own-crop and competing crop prices, $w_{i k, t_{i, k}}$ refers to prices of variable inputs (such as fertilizer), $\mathrm{YS}_{i k, t_{i, k}}$ refers to a yield shock for each crop, $\mu_{i t}$ are time dummies to account for some structural changes or national policy changes, $\eta_{i k}$ denote countryfixed effects to control for time-invariant heterogeneity across countries, and $u_{i k t}$ is the idiosyncratic shock. $\pi_{i}, \alpha_{i j}, \varphi_{i j}, \lambda_{i 1}$, and $\lambda_{i 2}$ are parameters to be estimated. The parameter $\alpha_{i j}$ can, for instance, be interpreted as an own-price supply elasticity if $j=i$ and as a cross-price supply elasticity if $j \neq i$. The subscript $k$ denotes the country. The subscripts $i$ and $k$ on $t$ indicate that the lag lengths of the following are country and crop specific: the relevant futures and spot prices, output price volatility, input price, and yield shock variables.

As discussed above, the seasonality of agricultural cultivation in different countries enables us to construct international prices that are country-specific variables 
at the seasonally appropriate time according to a country's crop calendar. This approach is more precise than assuming all countries face the same yearly output prices. This is particularly important because planting decisions in the early months of a calendar year (or marketing year) in some countries affect the annually averaged prices and would cause an endogeneity problem in any global supply response models that use annual data. Likewise, if planting decisions are made later in a calendar or marketing year, an average annual price will contain past prices that dilute the information signal that more recent planting-time prices could convey. ${ }^{4}$ Taking the lagged annual average price is not a good solution because producers adjust their price expectations according to more recent information (Just and Pope 2001).

As described in the conceptual model, the yield equation is specified similarly to Eq. (7.3) except that the output price and price volatility vectors do not include the price and volatility of competing crops. There is a subtle difference between the acreage response and yield response models in terms of the yield deviation measures used as proxies for yield expectations. In acreage response models, the yield deviation measures are derived from the harvest period prior to planting, but in yield response models, these measures are derived from the harvest in the previous year. Consequently, the deviations in the yield response models are lagged, whereas they are not necessarily lagged in the acreage response models if the prior harvest is in the year of planting. We therefore excluded these variables from the regressions of the production and yield response functions because they are, by definition, correlated with the respective lagged dependent variables. ${ }^{5}$ All quantities and output and input price variables (except for price volatilities, which are rates) are specified as logarithms in the econometric models. Hence, the estimated coefficients can be interpreted as short-run elasticities.

Applying ordinary least squares (OLS) estimation to a dynamic panel data regression model, such as in Eq. (7.3) above, results in a dynamic panel bias because of the correlation between the lagged dependent variable and the country-fixed effects (Nickell 1981). Since current acreage is a function of the fixed effects $\left(\eta_{k}\right)$, it is obvious that lagged acreage is also a function of these country-fixed effects. This violates the strict exogeneity assumption, and hence the OLS estimator is biased and inconsistent. An intuitive solution to this problem is to transform the data and remove the fixed effects. However, under the within-group transformation, the lagged dependent variable remains correlated with the error term, and therefore, the fixed-effects (FE) estimator is biased and inconsistent. While the correlation between the lagged dependent variable and the error term is positive in the simple OLS regression, the estimated coefficient of the lagged dependent variable is biased downward in the case of the FE estimator (Roodman 2009a, b).

\footnotetext{
${ }^{4}$ See Haile et al. (2014) for global intra-annual planting and harvesting patterns.

${ }^{5}$ The yield shock variables are not statistically significant in the acreage response models, and we omit them from the final regression.
} 
Therefore, we need an estimator of the true parameter that lies in the range between the OLS and the FE estimate for the coefficient on the lagged dependent variable. Anderson and Hsiao (1982) suggested using the instrumental variable (IV) method to estimate the first-difference model. This technique eliminates the fixedeffect terms by differencing instead of within transformation. Since the lagged dependent variable is correlated with the error term, this method uses the second lagged difference as an IV. Although this method provides consistent estimates, Arellano and Bond (1991) developed a more efficient estimator, called difference GMM, in order to estimate a dynamic panel difference model using all suitably lagged endogenous and other exogenous variables as instruments in the GMM technique (Roodman 2009a). Blundell and Bond (1998) developed a further strategy named system GMM to overcome dynamic panel bias. Instead of transforming the regressors to purge the fixed effects and using the levels as instruments, the system GMM technique transforms the instruments themselves in order to make them exogenous to the fixed effects (Roodman 2009a). The estimator in the difference GMM model can have poor finite sample properties in terms of bias and precision when applied to persistent series or random-walk types of variables (Roodman 2009b). The system GMM estimator allows substantial efficiency gains over the difference GMM estimator provided that initial conditions are not correlated with fixed effects (Blundell and Bond 1998). Thus, we have chosen the system GMM method to estimate our dynamic supply models.

Several statistical tests were conducted to check the consistency of our preferred GMM estimator. First, the Arellano-Bond test for autocorrelation is used to test for serial correlation in levels. The test results, reported in the next section, indicate that the null hypothesis of no second-order autocorrelation in residuals cannot be rejected for nearly all production, acreage, and yield models, indicating the consistency of the system GMM estimators. Second, the Hansen test results cannot reject the null hypothesis of instrument exogeneity. We also conducted a test for the validity of the Blundell-Bond assumption using the Diff-in-Hansen test of the two-step system GMM. The test statistics gave $p$-values greater than $10 \%$ in all cases, suggesting that past changes are good instruments of current levels and that the system GMM estimators are more efficient. Furthermore, the standard error estimates for all specifications are robust in the presence of any pattern of heteroskedasticity and autocorrelation within panels. The Windmeijer (2005) twostep error bias correction is incorporated. Following Roodman (2009a, b), we also "collapsed" the instrument set in order to limit instrument proliferation.

\subsection{Results}

\subsubsection{Econometric Results}

Tables 7.2 and 7.3 present the GMM results of the production/acreage and yield response functions, respectively. For each crop, we estimated the supply models using preplanting month spot prices and harvest period futures prices (except for 


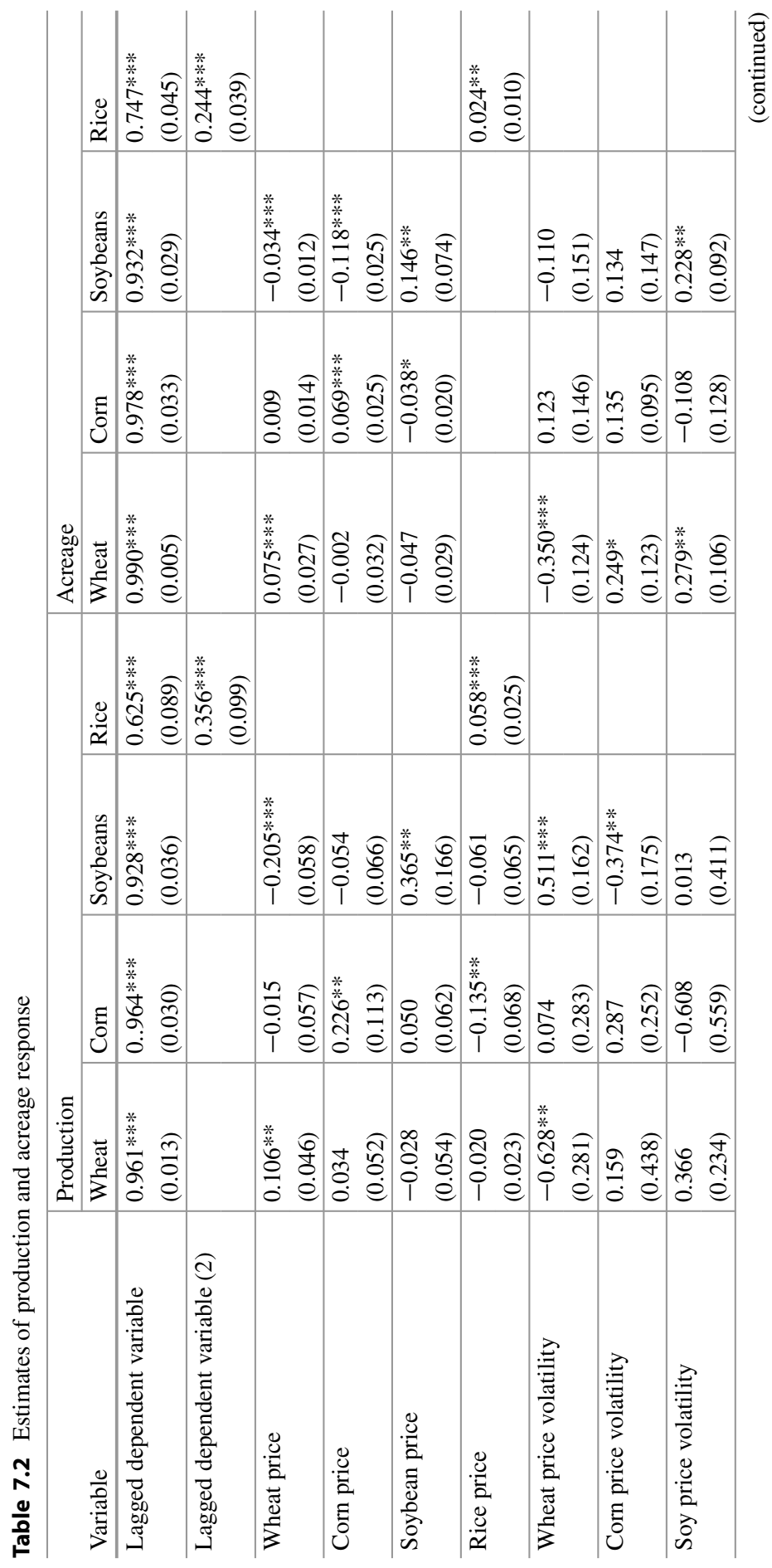




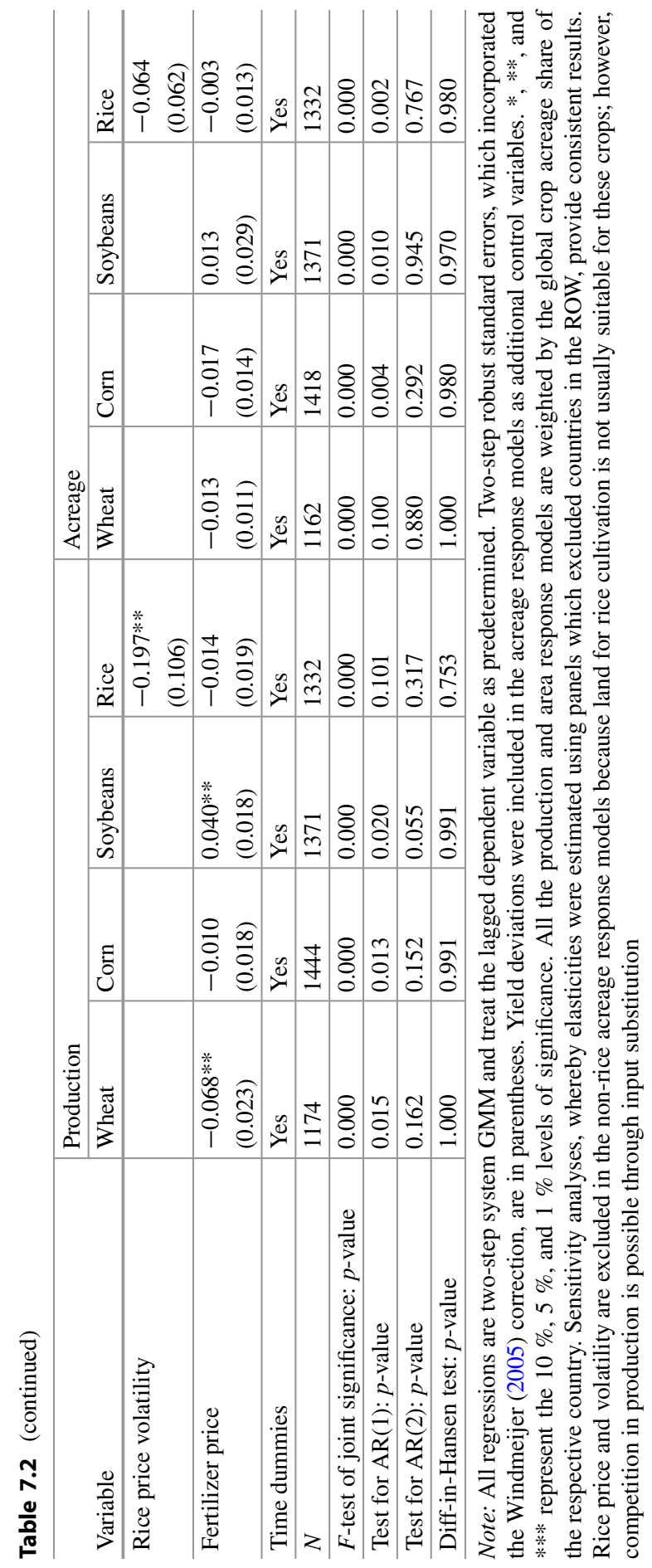


Table 7.3 Estimates of yield response

\begin{tabular}{l|l|l|l|l}
\hline Variable & Wheat & Corn & Soybeans & Rice \\
\hline Lagged dependent variable & $\begin{array}{l}0.920^{* * *} \\
(0.032)\end{array}$ & $\begin{array}{l}0.960^{* * *} \\
(0.020)\end{array}$ & $\begin{array}{l}0.925^{* * *} \\
(0.034)\end{array}$ & $\begin{array}{l}0.724 * * * \\
(0.133)\end{array}$ \\
\hline Lagged dependent variable & & & & 0.272 \\
& & & $0.165)$ \\
\hline Own-crop price & $0.166^{* * *}$ & $0.094^{* *}$ & $0.146^{* * *}$ & $0.043^{* *}$ \\
& $(0.055)$ & $(0.039)$ & $(0.045)$ & $(0.018)$ \\
\hline Own-price volatility & $-0.336^{* *}$ & $-0.366^{* *}$ & $-0.467 * *$ & $-0.148^{* *}$ \\
\hline Fertilizer price & $(0.168)$ & $(0.170)$ & $(0.226)$ & $(0.070)$ \\
\hline Time dummies & $-0.069^{* *}$ & -0.008 & $-0.050^{* *}$ & -0.020 \\
\hline$N$ & $(0.026)$ & $(0.021)$ & $(0.020)$ & $(0.017)$ \\
\hline$F$-test of joint significance: $p$-value & Yes & Yes & Yes & Yes \\
\hline Test for AR(1): $p$-value & 1174 & 1444 & 1371 & 1332 \\
\hline Test for AR(2): $p$-value & 0.000 & 0.000 & 0.000 & 0.000 \\
\hline Diff-in-Hansen test: $p$-value & 0.046 & 0.001 & 0.000 & 0.016 \\
\hline$N$-val & 0.950 & 0.749 & 0.933 & 0.751 \\
\hline
\end{tabular}

Note: All regressions are two-step system GMM and treat the lagged dependent variable as predetermined. Two-step robust standard errors, which incorporated the Windmeijer (2005) correction, are in parentheses. *, **, and *** represent the $10 \%, 5 \%$, and $1 \%$ levels of significance

rice) as proxies for expected prices at planting time. ${ }^{6}$ We failed to find a significant supply-price relationship using futures prices (except for soybeans); this could imply that many agricultural producers do not make use of information on futures prices in forming their price expectations. Indeed, futures prices are good proxies for expected prices for producers in countries where domestic prices are strongly linked to the futures prices- that is, where the maturity basis is constant. Although the farmers in advanced economies participate widely in futures markets and the futures prices are linked to the cash prices, this is not the case in many developing countries. Thus, we reported the results obtained from the specifications with spot prices.

Production, acreage, and yield responses to own prices are generally positive and statistically significant, and the results are consistent with economic theory. The results suggest that higher output prices induce producers to increase acreage and to invest in improving crop yields, implying that global food supply response to prices appears to occur through both acreage and yield changes. The production responses to own prices are larger than the respective acreage and yield responses (with the exception of the wheat yield response). The acreage and yield own-price elasticities are mostly similar in their order of magnitude.

\footnotetext{
${ }^{6}$ Rice futures markets have relatively short time series data, and local prices are unlikely to be strongly correlated with futures prices in several countries.
} 
The results show that soybeans and corn have the largest production responses to own-crop prices, followed by wheat and rice. Conditional on other covariates, a $10 \%$ rise in the expected own-crop price induces a production increase of about $4 \%$ for soybeans, $2 \%$ for corn, $1 \%$ for wheat, and $0.6 \%$ for rice in the short run. These production responses typically reflect the acreage and yield adjustments. An equivalent increase in the respective international crop prices induces farmers to increase their land allocated to soybean and corn cultivation by about $1.5 \%$ and $0.7 \%$, respectively. The yield of soybeans and corn also respond to higher international own-crop prices in an order of magnitude similar to their respective acreage responses; the short-run elasticities are 0.15 and 0.09 , respectively. Global wheat acreage and yield also respond to output prices, with short-run elasticities of 0.08 and 0.17 , respectively. In line with the production response results, rice has relatively weaker acreage and yield responses to own prices. Rice cultivation in some areas requires capital investment (such as for building canals and sluices) to ensure flooding at the time of planting. These investments are long-term decisions, implying that short-run price responses are inevitably low.

Additionally, the statistically significant cross-price elasticities have negative signs, and this is consistent with economic theories. Higher wheat prices are negatively correlated with soybean production, and corn producers respond to higher international rice prices by lowering corn production. The cross-price elasticities show that corn and soybeans compete for land at the global level, with a stronger corn price effect on soybean acreage than vice versa. In addition, higher international wheat prices lead to less land for soybean production.

Unlike own-crop price levels, own-price volatility does not have a uniform effect on the supply of all crops. Price volatility seems to affect wheat and rice production most. The results reveal that an increase in the volatility of international wheat and rice prices causes producers to allocate less land to these crops and reduce yield-improving investments, resulting in a decline in wheat and rice production. To some extent, the negative wheat acreage response to own-price volatility could be offset if prices of competing crops such as corn and soybeans also exhibit such volatility. For corn, the negative supply impact of own-price volatility is due mainly to declining yields. Corn producers react to rising own-crop prices by using more inputs to improve productivity, whereas corn price risk induces producers to shift inputs away from corn production. For soybean acreage, on the other hand, the estimated coefficient of own-price volatility has a statistically positive sign. This result is consistent with previous national-level studies that found either insignificant or positive effects of price volatility on soybean acreage (e.g., de Menezes and Piketty 2012). The majority of soybean producers in the world are large, commercial holders who are likely to be well informed about price developments. Thus, they may be willing and able to absorb price risks.

It is worth mentioning that the coefficients of the price volatility variablesmeasured by the standard deviation of log price returns-are not elasticities, and hence they are not directly comparable with the price elasticity estimates. We computed the standardized effect sizes of price and volatility on the respective supply responses to shed light on the relative effect sizes of the mean response when compared with the volatility responses (4). The effect sizes in Table 7.4 show the 


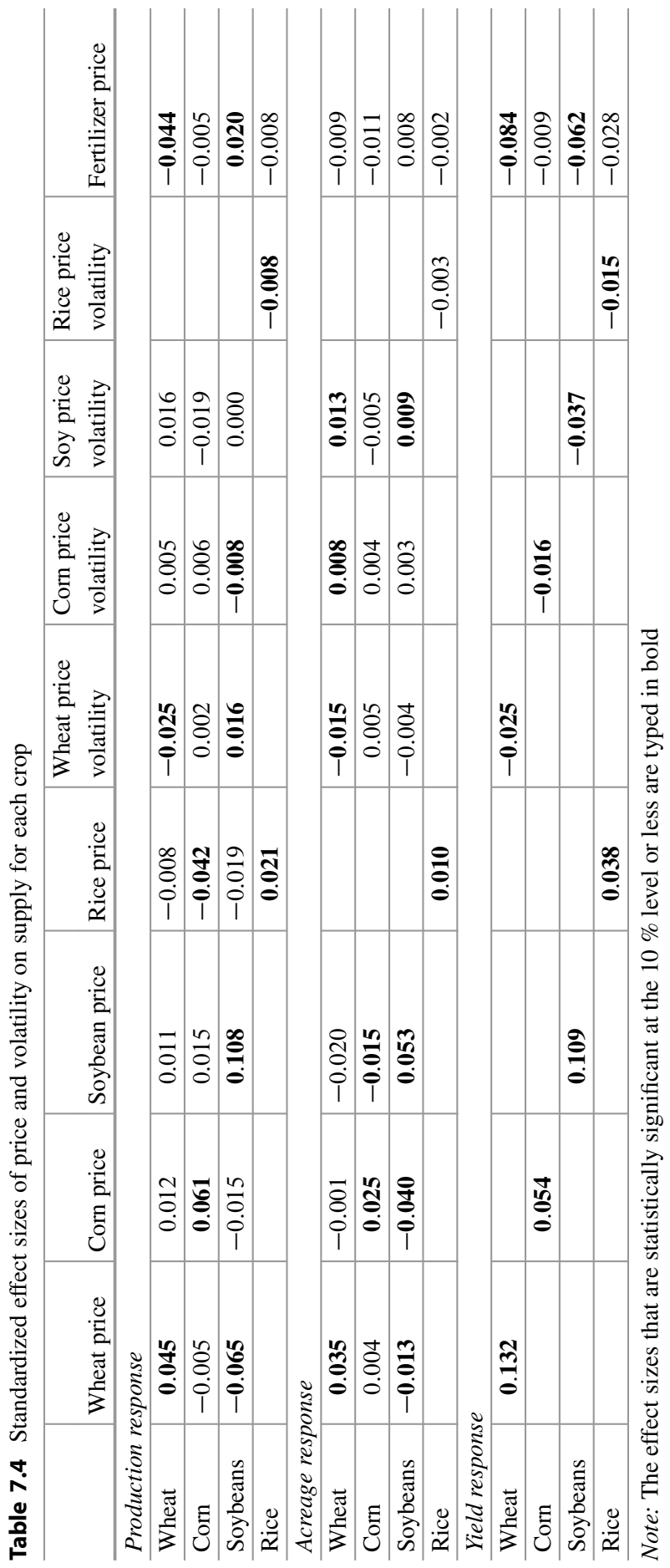


global supply response for a one standard deviation change in price and volatility for every crop. In the case of the effect sizes for wheat, the negative impact of own-price volatility on production and area is roughly half of the positive impact of own-price increase. Own-price volatility is also an important factor for the yields of all four crops, with effect sizes ranging between 19 and $34 \%$ of the yield responses to own-crop prices.

In addition to output prices, input prices are also an important factor in farmers' production decisions, as shown by fertilizer price elasticities. Higher international fertilizer prices not only have a negative effect on wheat production but also reduce the yields of nearly all crops. A doubling of international fertilizer price indices results in a $1-7 \%$ reduction in crop productivity.

The lagged dependent variables are both statistically and economically relevant in all crop supply models. ${ }^{7}$ The estimated coefficients indicate producers' inertia, which may reflect the adjustment costs of crop rotation, crop-specific land (and other quasi-fixed and fixed inputs), technology, and soil-quality requirements. The coefficients of the lagged dependent variables, however, may also reflect unobservable dynamic factors, and any interpretations should be made with caution (Hausman 2012). The estimated coefficients of the lagged dependent variables are close to one, indicating that agricultural supply is much more responsive to international output prices in the longer term than in the short term.

\subsubsection{Robustness Checks}

We have conducted several statistical tests to check the consistency of our preferred GMM estimator; and a number of additional sensitivity checks were performed to investigate the sensitivity of our results to alternative estimators. ${ }^{8}$ Results are generally robust in terms of the significance and sign of the control variables in most specifications.

The coefficients on the lagged dependent variable of our preferred GMM estimator are mostly close to unity, potentially suggesting remaining residual serial correlation. To this end, we conducted the Arellano-Bond test for first- and secondorder autocorrelated disturbances in the first-differenced equation. The $p$-values reported for $\mathrm{AR}(1)$ and $\mathrm{AR}(2)$ indicate that, as expected, there is a high firstorder autocorrelation and no evidence of significant second-order autocorrelation. However, for any remaining serial correlations and whenever the $p$-values of $\operatorname{AR}(2)$ are below 0.15 - for instance, in the production and yield response models for soybeans and in the latter model for wheat-we use second- and higher-order lags of the predetermined variable as instruments. Moreover, the coefficients of the lagged dependent variable can be statistically distinguished from unity in most cases. Another useful check for the validity of the dynamic panel estimates is to

\footnotetext{
${ }^{7}$ Rice cultivation requires capital investment to ensure flooding at the time of planting, which is a long-term investment. To account for such dynamics, we include a second lag of the dependent variable as a control variable.

${ }^{8}$ Alternative model results are available upon request.
} 
determine if the estimated coefficient on the lagged dependent variable lies between the values obtained from OLS and FE estimators. All our preferred system GMM specifications result in an estimated autoregressive coefficient that lies between the two bounds.

We also report the two-step difference GMM estimates, which are mostly consistent with their system GMM counterparts. Nevertheless, the autoregressive coefficient of the difference GMM (in most cases) lies below the lower credible bound as given by the FE estimator. In addition, as discussed in the empirical model, the difference GMM estimator does not take into account the high persistence of the dependent variable. Although we do not reject the null hypothesis of the validity of the overidentifying restrictions in all the difference and system GMM estimators, the Diff-in-Hansen test results validate the additional moment restriction necessary for the system GMM.

Several things have changed over the period from which our empirical data were obtained, including the information technology available to form price expectations, general inflation, and market- and government-based institutions to provide risk management. Thus, we checked whether our estimated parameters are stable over the estimation period by estimating our supply response models with 20- and 30year rolling windows. Additionally, we include interaction of the price variables with a dummy variable for the period after 1985-dividing the data period equallyand the period dummy to test if these additional variables are statistically different from zero. We also estimated the system GMM model on the subsample of our data after 1985; however, the estimation results are not reported for brevity. In general, the results of the recursive rolling estimation and the "Chow" test hint that the estimated coefficients are mostly stable over time and do not significantly change between the two periods. Moreover, the results from the estimations using the subsample data are mostly consistent with the results from our preferred model.

In summary, our empirical results align with previous work that showed that agricultural supply is inelastic in the short run. Table 7.5 summarizes the supply elasticities of selected countries as estimated by the Food and Agricultural Policy Research Institute (FAPRI) and in other literature; these estimates do not, however, capture the effects of price volatility on supply. The supply elasticity from Roberts and Schlenker (2009) is aggregated for all four crops in terms of their caloric content. Apart from the corn supply elasticity, which is larger in the present study, our other estimated elasticities are of similar order of magnitude to the weighted average of the national-level estimates. 
Table 7.5 Summary of existing own-price supply elasticities (without considering volatility)

\begin{tabular}{|c|c|c|c|c|}
\hline Country & Wheat & Corn & Soybeans & Rice \\
\hline Egypt & 0.25 & 0.09 & 0.03 & 0.16 \\
\hline South Africa & 0.09 & 0.28 & 0.03 & 0.03 \\
\hline China & 0.09 & 0.13 & 0.45 & 0.16 \\
\hline India & 0.29 & 0.21 & 0.36 & 0.11 \\
\hline Pakistan & 0.23 & 0.28 & 0.29 & 0.29 \\
\hline Argentina & 0.41 & 0.7 & 0.32 & 0.24 \\
\hline Brazil & 0.43 & 0.42 & 0.34 & 0.07 \\
\hline Turkey & 0.20 & 0.14 & & 0.47 \\
\hline Iran & 0.08 & 0.01 & 0.01 & 0.01 \\
\hline EU & 0.12 & 0.08 & 0.19 & 0.24 \\
\hline Russia & 0.19 & 0.31 & & \\
\hline Canada & 0.39 & 0.18 & 0.32 & \\
\hline USA & 0.25 & 0.17 & 0.30 & 0.35 \\
\hline Australia & 0.33 & 0.23 & & 0.17 \\
\hline Weighted average (weighted by area share) & 0.18 & 0.14 & 0.31 & 0.07 \\
\hline Roberts and Schlenker (2009), Global & \multicolumn{4}{|c|}{0.11} \\
\hline Roberts and Schlenker (2013), Global & 0.10 & 0.27 & 0.55 & 0.03 \\
\hline Haile et al. (2014) & 0.09 & 0.18 & 0.37 & 0.02 \\
\hline This study & 0.11 & 0.23 & 0.37 & 0.06 \\
\hline
\end{tabular}

Source: Food and Agricultural Policy Research Institute (FAPRI), FAPRI Elasticity Database, http://www.fapri.iastate.edu/tools/elasticity.aspx. Because FAPRI only reports rice acreage elasticities for the USA, for the other crops, we used elasticities from Lin and Dismukes (2007). We also use average acreage elasticities for "other Africa" for unreported elasticities for Egypt and South Africa. Price elasticities for individual countries refer to acreage responses to domestic producer prices, while global price elasticities for this study refer to responses to world market prices

\subsubsection{Simulation Results}

We used the estimated coefficients of our preferred GMM estimator in Tables 7.2 and 7.3 to analyze whether the recent increase in prices and price volatility is an opportunity or a challenge to world food supply, in terms of acreage and yield changes. To this end, we calculate the differences in the predicted outcome variables under the realized prices and under a counterfactual scenario where all output prices and volatility as well as fertilizer prices after 2006 are set equal to their 19802005 mean values. We consider only the direct short-term impacts and neglect the influence of the autoregressive term, which would further exacerbate the changes in the long run. The results of these simulations are shown in Figs. 7.1 and 7.2.

The net impact of increasing own and competing crop prices is about a $2 \%$ increase in the area used for cultivating both wheat and corn. The effect is higher $(6 \%)$ for rice as we included only own prices in the rice acreage. However, the effect of higher competing crop prices on soybean acreage offsets that of higher own-crop prices, resulting in a negligible net effect. In contrast, increasing fertilizer prices reduces acreage by nearly comparable amounts, except for soybeans, where 


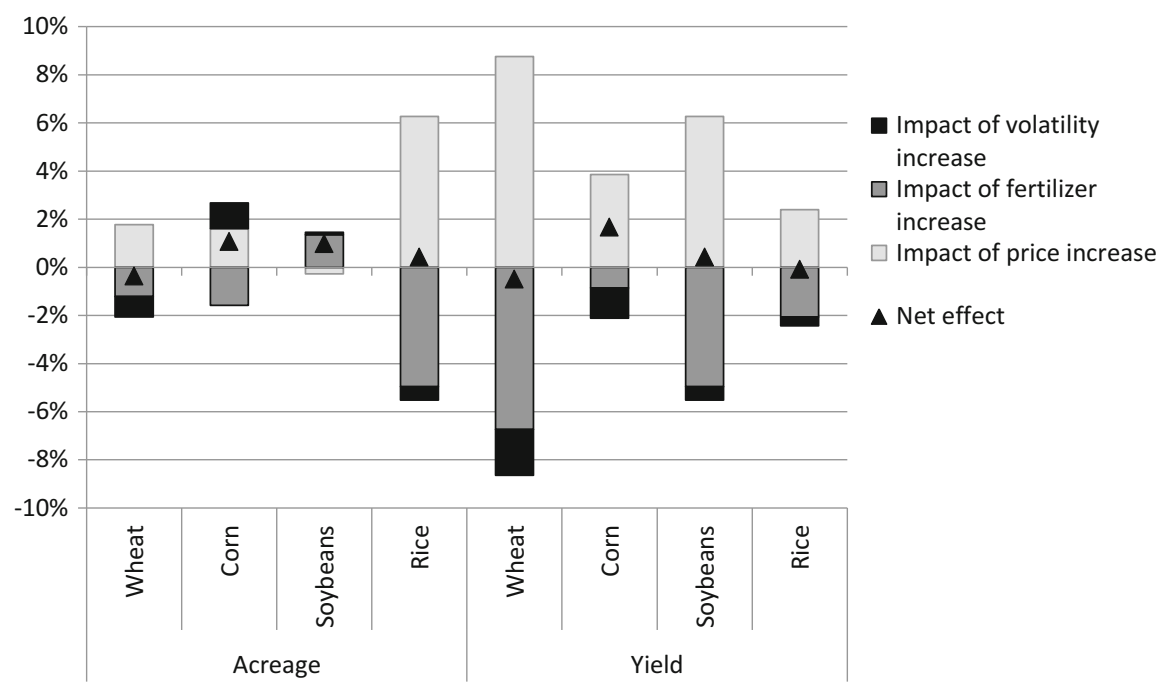

Fig. 7.1 Impacts of the 2006-2010 price dynamics on acreage and yield. Note: The figure shows the impact of output and fertilizer prices and output price volatility on acreage and yield compared with a counterfactual scenario where these values were set to their long-term average. The net effect is calculated as the sum of the three components. The depicted rates refer to the net impacts during the 5-year period 2006-2010. These changes are the direct short-term response, and they are the lower bounds for the longer-term effects as the coefficients of the autoregressive term are positive and closer to unity

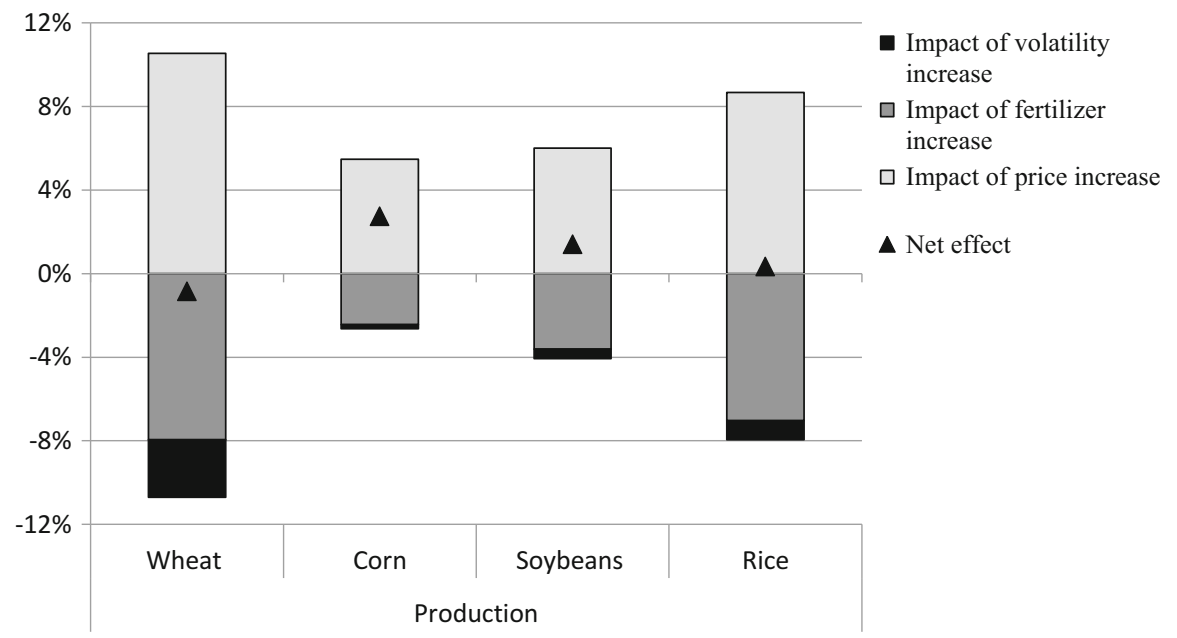

Fig. 7.2 Impacts of the 2006-2010 price dynamics on production. Note: See simulation assumptions detailed in Fig. 7.1 
it has a positive effect. ${ }^{9}$ The coefficient for volatility is statistically insignificant for corn, but higher volatility affects wheat acreage negatively and soybean acreage positively. The overall impact of the 2006-2010 output and input price dynamics on acreage is estimated to be, on average, positive for corn, soybeans, and rice and slightly negative for wheat. The different price dynamics have greater impacts on yields, but because of strong opposing effects, the net impact is similar in magnitude to the impact on acreage allocation decisions. The increase in own-crop price volatility during the same period dampens yield by about $1-2 \%$ for the crops under consideration.

Analogously, we calculated the production impact of the recent price dynamics from the acreage and yield simulations by the identity that production equals acreage times yield. This way, we rely on the two-stage decision process whereby acreage and yield decisions are temporally decoupled. The respective results are shown in Fig. 7.2. According to the results, the overall net impact of the 2006-2010 price dynamics on production is about a $3 \%$ increase for corn, a $1.5 \%$ increase for soybeans, negligible for rice, and a $1 \%$ decrease for wheat. Decomposing the overall effect into output price, fertilizer price, and price volatility effects reveals interesting results. The net impact of increasing own and competing crop prices ranges from about a $6 \%$ (for corn and soybeans) to $11 \%$ (for wheat) increase in production. In contrast, the effect of higher fertilizer price is a reduction of production that ranges from about $2 \%$ for corn to $8 \%$ for wheat. The effect of own-crop price and competing crop-price volatility is about a $3 \%$ decrease in production for wheat and about $1 \%$ for rice; it has a negative but negligible effect on the production of corn and soybeans.

In summary, the simulation results show that more volatile output prices and higher input prices have weakened the extent to which rising international agricultural commodity prices might have increased output production since the middle of the last decade.

\subsection{Conclusions}

Uncertainty is a quintessential feature of agricultural commodity prices. Besides the traditional causes of price fluctuations, agricultural commodities are increasingly connected to energy and financial markets, with potentially destabilizing impacts on prices (Tadesse et al. 2014). Using cross-country panel data for the period 19612010, this study has investigated the global supply impacts of international price levels and price volatility. Estimation of the recent supply response to input and output price levels and to output price volatility is a necessary step in predicting the effects that developments in output price levels and volatility have on the global food supply in the future. In addition to responding to price changes by reallocating

\footnotetext{
${ }^{9}$ One explanation for this is that soybeans require less nitrogen fertilizer than the other crops, which makes planting them more attractive when fertilizer prices are high.
} 
acreage, producers react to expected price changes by making decisions that affect yields.

The results underscore the relevance of output price volatility for the supply of the key global agricultural staple crops. Although higher risk in prices is usually associated with higher returns, economic theory has shown that output price risk is detrimental to producers (Sandmo 1971). Coefficients for the price-risk variables are statistically and economically significant in the supply response models for wheat and rice and in the yield response models for all crops. Besides inducing producers to shift land away from wheat and rice cultivation, higher output price volatility weakens the incentive for producers to invest in yield improvement. For corn, owncrop price volatility has little or no impact on acreage allocation, but it has a negative impact on yield.

Consequently, reducing agricultural price volatility is likely to increase food supply globally and, more importantly, in developing countries. Some agricultural producers, however, do not shy away from making investments in order to obtain higher returns, which are associated with higher price risks. Such producers are not necessarily hurt by output price volatility. The findings of this paper suggest that this is the case for the majority of soybean producers in the world, indicated by the statistically significant positive coefficient of own-price volatility in the acreage response model. This result is relevant for policymakers because it suggests that a one-size-fits-all approach to price volatility management-such as through stockholding or public price risk insurance systems - may not be appropriate.

This paper has explained why the current high food prices have not brought about a large increase in global agricultural supply as one might expect. The estimated short-run supply elasticities are generally small. Agricultural supply does not increase on a par with output price increases in the short run. In other words, agricultural producers need more time to make necessary production adjustments and investments to increase supply. Furthermore, this study has assessed how much the increased latent output price uncertainty, represented by price volatility, weakens the global positive supply response.

Acknowledgment The authors acknowledge financial support from Bayer CropScience AG, the European Commission (FoodSecure Research Project), and the Federal Ministry of Economic Cooperation and Development of Germany (Research Project on Commodity Price Volatility, Trade Policy and the Poor).

\section{A.1 Appendix}




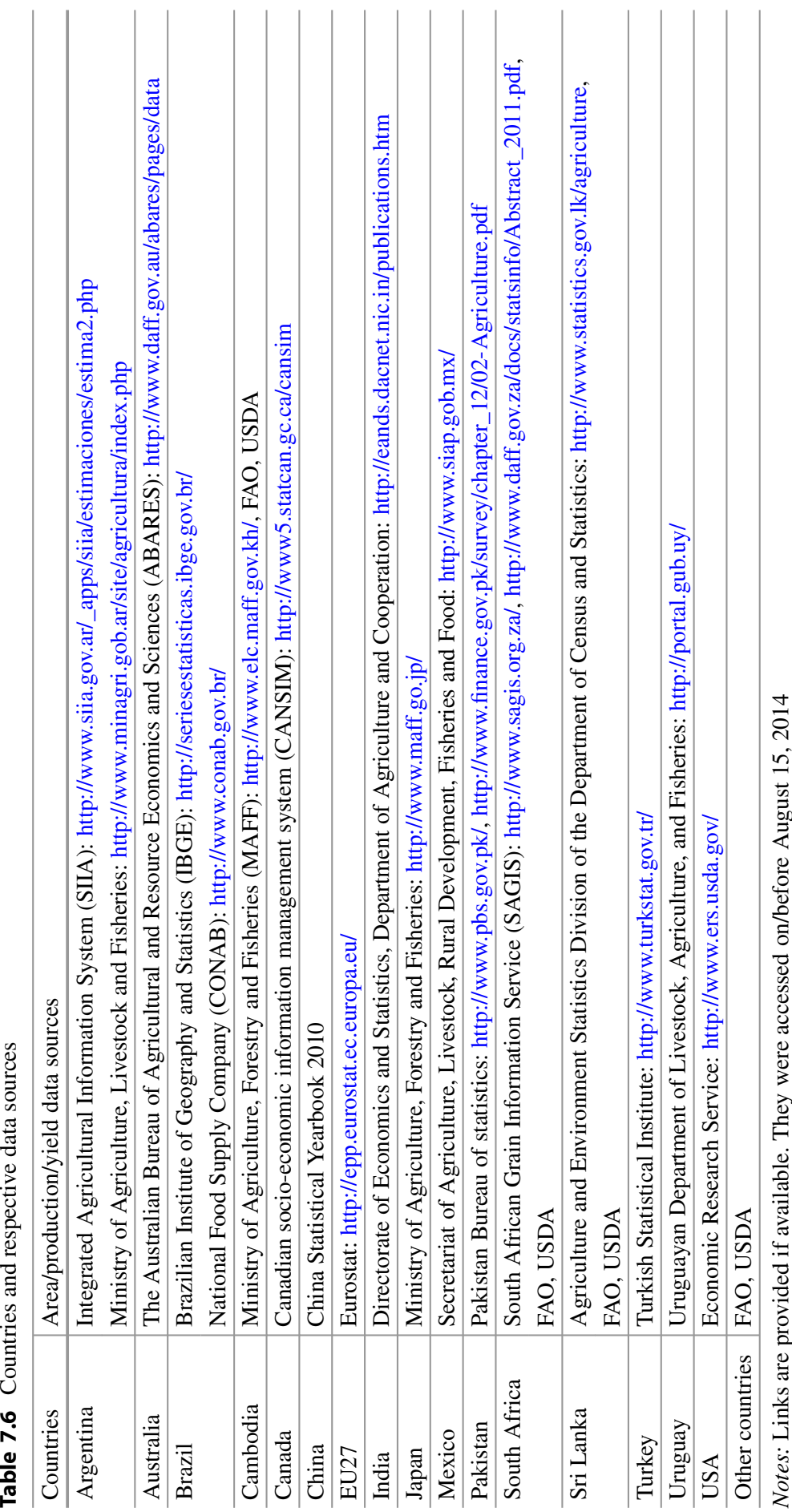


Open Access This chapter is distributed under the terms of the Creative Commons AttributionNoncommercial 2.5 License (http://creativecommons.org/licenses/by-nc/2.5/) which permits any noncommercial use, distribution, and reproduction in any medium, provided the original author(s) and source are credited.

The images or other third party material in this chapter are included in the work's Creative Commons license, unless indicated otherwise in the credit line; if such material is not included in the work's Creative Commons license and the respective action is not permitted by statutory regulation, users will need to obtain permission from the license holder to duplicate, adapt or reproduce the material.

\section{References}

Abbott PC, Hurt C, Tyner WE (2011) What is driving food prices in 2011? Farm Foundation, Issue Reports, Oak Brook, IL

Anderson TW, Hsiao C (1982) Formulation and estimation of dynamic models using panel data. J Econometrics 18(1):47-82

Aradhyula SV, Holt MT (1989) Risk behavior and rational expectations in the US broiler market. Am J Agric Econ 71(4):892-902

Arellano M, Bond S (1991) Some tests of specification for panel data: Monte Carlo evidence and an application to employment equations. Rev Econ Stud 58(2):277-297

Askari H, Cummings JT (1977) Estimating agricultural supply response with the Nerlove model: a survey. Int Econ Rev 18(2):257-292

Baquedano FG, Liefert WM (2014) Market integration and price transmission in consumer markets of developing countries. Food Policy 44:103-114

Barr KJ, Babcock BA, Carriquiry MA, Nassar AM, Harfuch L (2009) Agricultural land elasticities in the United States and Brazil. Appl Econ Perspect Policy 33(3):449-462

Bellemare M, Barrett C, Just D (2013) The welfare impacts of commodity price volatility: evidence from rural Ethiopia. Am J Agric Econ 95(4):877-899

Binswanger HP, Rosenzweig MR (1986) Behavioural and material determinants of production relations in agriculture. J Dev Stud 22(3):503-539

Binswanger H, Yang MC, Bowers A, Mundlak Y (1987) On the determinants of cross-country aggregate agricultural supply. J Econometrics 36(1-2):111-131

Blundell R, Bond S (1998) Initial conditions and moment restrictions in dynamic panel data models. J Econometrics 87(1):115-143

Braulke M (1982) A note on the Nerlove model of agricultural supply response. Int Econ Rev 23(1):241-244

Chavas JP (2000) On information and market dynamics: the case of the US beef market. J Econ Dynam Contr 24(5-7):833-853

Coyle BT (1993) On modeling systems of crop acreage demands. J Agric Resource Econ 18(1):57-69

Coyle BT (1999) Risk aversion and yield uncertainty in duality models of production: a meanvariance approach. Am J Agric Econ 81(3):553-567

de Menezes TA, Piketty M-G (2012) Towards a better estimation of agricultural supply elasticity: the case of soya beans in Brazil. Appl Econ 44(31):4005-4018

Eckstein Z (1984) A rational expectations model of agricultural supply. J Pol Econ 92(1):1-19

Ezekiel M (1938) The cobweb theorem. Q J Econ 52(2):255-280

Gardner BL (1976) Futures prices in supply analysis. Am J Agric Econ 58(1):81-84

Gilbert CL, Morgan CW (2010) Food price volatility. Phil Trans R Soc B Biol Sci 365(1554):30233034

Goodwin BK, Marra M, Piggott N, Mueller S (2012) Is yield endogenous to price? An empirical evaluation of inter-and intra-seasonal corn yield response. North Carolina State University 
Haile MG, Kalkuhl M, von Braun J (2014) Inter- and intra-seasonal crop acreage response to international food prices and implications of volatility. Agric Econ 45(6):693-710

Hausman C (2012) Biofuels and land use change: sugarcane and soybean acreage response in Brazil. Environ Resource Econ 51(2):163-187

Hendricks NP, Janzen JP, Smith A (2015) Futures prices in supply analysis: are instrumental variables necessary? Am J Agric Econ 97(1):22-39

Hendricks NP, Smith A, Sumner DA (2014) Crop supply dynamics and the illusion of partial adjustment. Am J Agric Econ 96(5):1469-1491

Holt MT, McKenzie AM (2003) Quasi-rational and ex ante price expectations in commodity supply models: an empirical analysis of the US broiler market. J Appl Econometrics 18(4):407-426

Houck JP, Ryan ME (1972) Supply analysis for corn in the United States: the impact of changing government programs. Am J Agric Econ 54(2):184-191

Imai KS, Gaiha R, Thapa G (2011) Supply response to changes in agricultural commodity prices in Asian countries. J Asian Econ 22(1):61-75

Just RE, Pope RD (2001) The agricultural producer: theory and statistical measurement. In: Gardner BL, Rausser GC (eds) Handbook of agricultural economics. Elsevier, Amsterdam

Kalkuhl M (2014) How strong do global commodity prices influence domestic food prices? A global price transmission analysis. Zef-Discussion paper on development policy no. 191. Center for Development Research, Bonn

Lansink AO (1999) Area allocation under price uncertainty on Dutch arable farms. J Agric Econ 50(1):93-105

Lee DR, Helmberger PG (1985) Estimating supply response in the presence of farm programs. Am J Agric Econ 67(2):193-203

Liang Y, Corey Miller J, Harri A, Coble KH (2011) Crop supply response under risk: impacts of emerging issues on Southeastern US agriculture. J Agric Appl Econ 43(2):181

Lin W, Dismukes R (2007) Supply response under risk: implications for counter-cyclical payments' production impact. Appl Econ Perspect Policy 29(1):64

Miranda MJ, Helmberger PG (1988) The effects of commodity price stabilization programs. Am Econ Rev 78(1):46-58

Moschini G, Hennessy DA (2001) Uncertainty, risk aversion, and risk management for agricultural producers. Handbook Agric Econ 1(A):88-153

Mundlak Y, Larson D (1992) On the transmission of world agricultural prices. World Bank Econ Rev 6(3):399-422

Muth JF (1961) Rational expectations and the theory of price movements. Econometrica 29(3):315-335

Nelson RG, Bessler DA (1992) Quasi-rational expectations: experimental evidence. J Forecast 11(2):141-156

Nerlove M (1956) Estimates of the elasticities of supply of selected agricultural commodities. J Farm Econ 38(2):496-509

Nerlove M (1958) Adaptive expectations and cobweb phenomena. Q J Econ 72(2):227-240

Nerlove M, Bessler DA (2001) Expectations, information and dynamics. Handbook Agric Econ Vol 1, Part A: 155-206

Nerlove M, Fornari I (1998) Quasi-rational expectations, an alternative to fully rational expectations: an application to US beef cattle supply. J Econometrics 83(1):129-161

Nickell S (1981) Biases in dynamic models with fixed effects. Econometrica 49:1417-1426

Nickell S (1985) Error correction, partial adjustment and all that: an expository note. Oxf Bull Econ Stat 47:119-129

OECD (2008) Rising food prices: causes and consequences. Organisation for Economic CoOperation and Development (OECD), Paris

Peterson WL (1979) International farm prices and the social cost of cheap food policies. Am J Agric Econ 61(1):12-21

Rao JM (1989) Agricultural supply response: a survey. Agric Econ 3(1):1-22

Roberts MJ, Schlenker W (2009) World supply and demand of food commodity calories. Am J Agric Econ 91(5):1235-1242 
Roberts MJ, Schlenker W (2013) Identifying supply and demand elasticities of agricultural commodities: implications for the US ethanol mandate. Am Econ Rev 103(6):2265-2295

Roodman D (2009a) How to do xtabond2: an introduction to difference and system GMM in Stata. Stata J 9(1):86-136

Roodman D (2009b) A note on the theme of too many instruments. Oxf Bull Econ Stat 71(1):135-158

Sandmo A (1971) On the theory of the competitive firm under price uncertainty. Am Econ Rev 61(1):65-73

Shideed KH, White FC (1989) Alternative forms of price expectations in supply analysis for US corn and soybean acreages. West J Agric Econ 14(2):281-292

Subervie J (2008) The variable response of agricultural supply to world price instability in developing countries. J Agric Econ 59(1):72-92

Tadesse G, Algieri B, Kalkuhl M, von Braun J (2014) Drivers and triggers of international food price spikes and volatility. Food Policy 47:117-128

Vitale JD, Djourra H, Sidib A (2009) Estimating the supply response of cotton and cereal crops in smallholder production systems: recent evidence from Mali. Agric Econ 40(5):519-533

Weersink A, Cabas JH, Olale E (2010) Acreage response to weather, yield, and price. Can J Agric Econ 58(1):57-72

Windmeijer F (2005) A finite sample correction for the variance of linear efficient two-step GMM estimators. J Econometrics 126(1):25-51

Yu B, Liu F, You L (2012) Dynamic agricultural supply response under economic transformation: a case study of Henan, China. Am J Agric Econ 94(2):370-376 